\title{
sciendo
}

CIVIL AND ENVIRONMENTAL ENGINEERING REPORTS

E-ISSN 2450-8594

CEER 2020; 30 (2): 0185-0199

DOI: $10.2478 /$ ceer-2020-0026

Original Research Article

\section{ESTIMATION OF THE ADHERENCE OF MORTARS USING ULTRASOUND}

\author{
Nacera KHALDI ${ }^{1}$, Mouloud BELACHIA ${ }^{2,3}$, Abdelhalim BENOUIS ${ }^{4}$ \\ ${ }^{1}$ Department of civil engineering, University of 20 August 1955, Skikda, \\ Algeria \\ ${ }^{2}$ LMGHU Laboratory, University of 20 August 1955, Skikda, Algeria \\ ${ }^{3}$ Department of civil engineering and hydraulics, University 8 May 1945, \\ Guelma, Algeria \\ ${ }^{4}$ Laboratory of Civil Engineering and hydraulics, University of 8 May \\ 1945, Guelma, Algeria
}

\begin{abstract}
Mortars are subjected to severe external stresses such as freezing, thawing, and drying during their lifetime. These stresses can lead to a loss of adhesion between the support and the mortar. The strength of the substrates with respect to their ability to receive a coating (mortar) is characterized in particular by the value of minimum tear resistance of the surface to be coated. In this work, the use of a non-destructive method which is both fast and easy to implement is employed to evaluate this support-mortar adhesion. The first method is based on the measurement of the velocities of the surface ultrasonic waves and the second by tearing tests using a specific dynamometer. The determination of the adhesion strength concerned two different supports (concrete beam and masonry block) coated with two types of mortar (a prepared cement mortar and a ready-to-use mortar) with two different thicknesses for each mortar (1 and $2 \mathrm{~cm}$, respectively). The results of the two methods are then correlated for an estimation of the adhesion of the mortars.
\end{abstract}

Keywords: mortar, support, adhesion, thickness, ultrasounds, pull-out

${ }^{1}$ Corresponding author: Po Box 26, el Hadeik road, Skikda, Algeria 2100, e-mail: khaldi.nacera@univ-guelma.dz 


\section{INTRODUCTION}

Construction is generally carried out using elements which must be secured or protected by a coating. These operations are usually done with a binder, always mixed with sand, water, and possibly an adjuvant to obtain a mortar. Mortar coatings can be dosed and tempered on site, or pre-dosed at the factory and requiring only a supply of water for mixing at the time of use (mortars ready for use).

For environmental needs or to improve certain properties, researchers have explored the substitution of natural sand by various additions in the mortar's composition.

Azevedo et al. [4] evaluated the potential for using the natural fibre of pineapple (Ananas comosus) as a reinforcing material in cement composites.

The results of other studies $[14,16]$ confirmed the possibility of partial replacement of hydrated lime by a kaolinitic clay or marble waste up to $50 \%$. Other research [3] worked to analyse the viability of incorporating granite residues to substitute sand in mortar coatings for building construction.

Construction and demolition waste (CDW) has also been considered as a replacement for natural sand. The results of this study indicate a $25 \%$ composition of CDW as being the most suitable for use in building construction [1].

Understanding the adhesion properties between a mortar and a support is a major challenge for manufacturers who try through more and more complex formulations to improve the performance of their products. Beyond the palatability of a mortar for a support (the chemical and physical compatibilities of the two materials), it is the durability of the link between the materials that is sought. However, mortars are subjected during their service to sometimes severe external stresses (drying, freezing / thawing, carbonation, etc.) that can lead to loss of adhesion [17].

Good preparation of the support will impact positively on the adhesion of the coating and its final appearance. Coatings are applied to substrates of differing nature: masonry or stone, bricks or concrete blocks, unbound rough-cast concrete, light aggregate concrete, cellular concrete, etc. Some supports allow direct application, as is the case with brick, concrete blocks, and stone masonry, whereas other materials require prior processing.

Proper adhesion of a coating to its support is fundamental; otherwise, one has a deterioration of the coating, which will detach in plates.

Taking red ceramic, known as substrates, as an example, the results indicate that firing temperature is a variable that directly influences the adhesive properties. Bricks burned at $950{ }^{\circ} \mathrm{C}$ provided a greater gain in resistance to the adhesion of traction due to the high initial absorption index compared with other bricks fired 
at lower temperatures [2]. Zanelato et al. indicated that the adoption of the intermediary adhesion mechanisms between the ceramic substrate and the mortar, referred to as "Roughcast", significantly increased the tensile bond strength, and altered the type of rupture seen in their tests [24].

The main adhesion defects seen are due, among others, to too smooth a support; rough form concrete with traces of demoulding oil or curing compounds; a dirty support with deposits of organic matter or with traces of old gypsum plaster this support will not be neutral since the plaster will then react on the cement of the mortar to give expansive products; too dry a support, which has not been sufficiently moistened before the projection of the first layer of attachment; poorly composed mortar, applied too late; or finally, a mortar with excessive shrinkage (binder overdose).

Adhesion can be defined as the force that must be provided to the adherent system to separate two constituents [13].

The use of ultrasound is one of the oldest methods for concrete characterization and is based on the measurement of the amplitude and travel time of an ultrasonic wave pulse over a known path length. Ultrasonic testing is important because of its ease of use and reasonable cost.

Rayleigh waves are mechanical waves propagating parallel to the surface of the solid material with an elliptical particle motion. They generally only penetrate the first centimetres of the surface; however, the depth of penetration of these waves depends on the frequency of the transducers $[8,19,20]$.

Velocity measurement techniques using contact transducers coupled to a sample of material with either a liquid coupling agent or solid bond are widely used in both the laboratory and in the field, and proper coupling is needed in order to transfer sufficient energy in the sample. These techniques have the advantage that they can be applied in situations where a large amount of incident wave energy is required or when the material to be characterized is very strongly attenuating and / or when the environmental conditions do not allow another method.

Several authors are working in contact to measure velocity and ultrasonic attenuation in cement-based materials [7, 11, 23, 26], wherein they are studying the relationships between velocity, attenuation and porosity, permeability, and segregation parameters. Other studies have indicated that it is possible to use UPTs for evaluation to qualify structural ceramic blocks [15].

This work consists of studying the relationships between the velocity of the indirect ultrasonic waves and the resistance to tearing (adhesion) of the mortar coatings, in order to have the possibility of estimating the characterization of the adhesion of the mortars in a non-destructive way to replace the destructive tearing tests. 
Two types of mortars were prepared and ready to use on two different supports (masonry and concrete) and with two thicknesses $(1$ and $2 \mathrm{~cm}$ ) for each mortar.

\section{MATERIALS AND EXPERIMENTATION}

\subsection{Characteristics of the materials used for the mortar}

For the preparation of our ready-to-use mortar (site), we used cement and support materials available and widely-used locally. Their characteristics were determined experimentally at the Civil Engineering and Hydraulic Laboratory (LGCH) of the University of Guelma, May 08, 1945.

Limestone sand, two types of crushed gravel (15/15 and 15/25), and CEM II-A class 42.5 cement with absolute and apparent densities of 3100 and $1120 \mathrm{~kg} / \mathrm{m} 3$ and a surface area of 3702 , respectively were used. The water used is that available at the LGCH Guelma laboratory.

Sand is the constituent of the granular skeleton that has the greatest impact on the mortar. It plays a key role in reducing volume variations and heat released. It must be clean and not contain any harmful elements. The characteristics of sand and gravel are shown in Tables 1 and 2.

Table 1. Physical characteristics of sand

\begin{tabular}{|c|c|c|c|}
\cline { 2 - 4 } \multicolumn{1}{c|}{} & \multicolumn{2}{c|}{ Equivalent of sand } & Compactness \\
\hline Characteristics & ESV (\%) & ESP $(\%)$ & C $(\%)$ \\
\hline Results & 80.43 & 77.08 & 64.51 \\
\hline
\end{tabular}

Table 2. Physical, mechanical, and chemical characteristics of gravel

\begin{tabular}{|l|c|c|}
\hline Designation & $5 / 15$ & $15 / 25$ \\
\hline Absolute density (g / cm3) & 2.57 & 2.58 \\
\hline Apparent density (g / cm3) & 1.582 & --- \\
\hline Gravel water content (\%) & 0.315 & 12.05 \\
\hline Coef. Los Angeles & 24.00 & --- \\
\hline Coef. micro-Deval "MD" & 20.00 & --- \\
\hline Insoluble (\%) & 09.10 & 10.40 \\
\hline Carbonates (\%) & 88.62 & 84.80 \\
\hline
\end{tabular}

Ready-to-use mortar (industrial) is a single-layer waterproofing and decorative mortar manufactured by Mortéro Sarl (Algeria). It is intended for exterior walls 
on supports of concrete blocks or brick. According to the standard NF2008, P 15-201-1-1[18], it presents the following performance characteristics: type - OC 3 , compressive strength - CS III, water absorption by capillarity - W2, reaction to fire - A1

\subsection{Dimensions and composition of the supports}

Two types of commonly used media have been chosen. The first is made of block, dimensions $15 \times 20 \times 40 \mathrm{~cm}$, and the second is a concrete beam, dimensions 15 x 15 x $100 \mathrm{~cm}$.

\subsubsection{Preparation of test bodies}

The two types of support were cleaned beforehand and the application of the mortar was made in two passes of $5 \mathrm{~mm}$ and $10 \mathrm{~mm}$, respectively, for the thickness of mortar of $1 \mathrm{~cm}$ and $2 \mathrm{~cm}$. The first pass must be erected and tightened but not smoothed to allow good adhesion of the second pass, as recommended

\subsection{Experimental methodology}

\subsubsection{Ultrasonic velocity measurement}

This method makes it possible to measure the propagation time of an ultrasonic pulse passing through the concrete. The main features of all devices available on the market are very similar. These devices include a pulse generator and a pulse receiver [12]. Ultrasonic velocity measurements were performed in the indirect transmission mode (surface waves), carried out by an ultrasonic tester 58-E0048 (Controls brand) comprising a transmission transducer and a receiving transducer of $54 \mathrm{kHz}$ frequency and $49.5 \mathrm{~mm}$ diameter [5]. The transducers are brought into contact with the faces of the test pieces via a couplant (Fig1). The receiving transducer was moved away from the transmitting transducer starting from a centre-to-centre separation, with an increment of $25 \mathrm{~cm}$ apart for the concrete and $10 \mathrm{~cm}$ for the breeze block. 

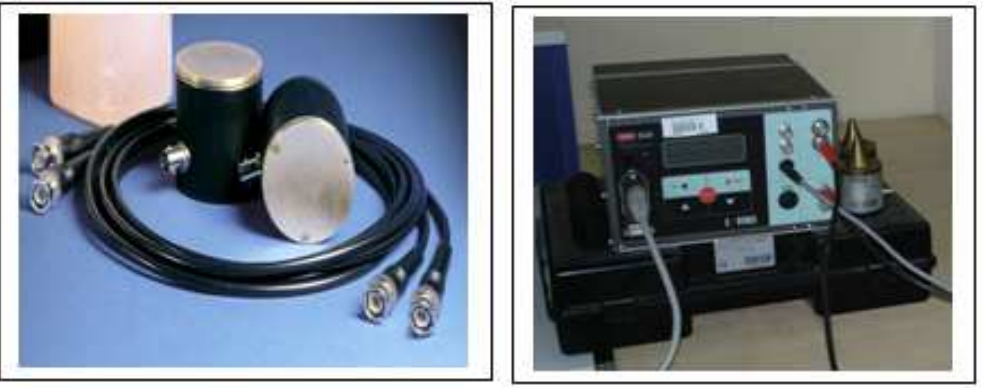

Fig. 1. Ultrasonic Apparatus

\subsubsection{Measuring the pulling force}

The peel test consists of adhering a metal pad to the coated surface and applying a tensile force to failure (Fig 2). The studs used in the context of this work are 50 $\mathrm{mm}$ wide aluminium studs. The NF EN 24624 standard [10] recommends making a notch in the coating all around the stud to the substrate. The force applied to the sample is gradually increased at a constant speed, up to a maximum force corresponding to the break. The pulling force is calculated as the ratio of the maximum force on the surface of the pad.

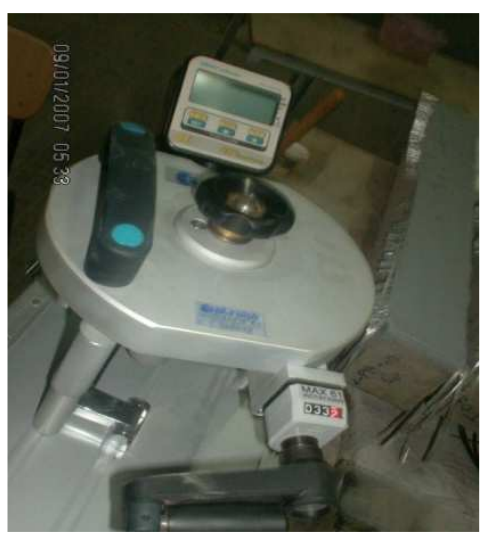

Fig. 2. Tensile force pull-out tests

The tests carried out on the supports were carried out in four positions, $25 \mathrm{~cm}$ apart for the concrete and $10 \mathrm{~cm}$ for the breeze block. Respectively as for the ultrasonic tests. 


\section{RESULTS AND DISCUSSION}

Non-destructive testing using ultrasound was conducted for steps between the transmitter and receiver of $25 \mathrm{~cm}$ and $10 \mathrm{~cm}$, respectively. These spacings are in accordance with the rule proposed by Tokimatsu and al [21], which recommends an L-spacing greater than four times the wavelength: $\lambda / \mathbf{4} \leq \mathbf{L}$. Our concrete is an ordinary concrete $(\mathrm{V} \geq 3000 \mathrm{~m} / \mathrm{s})$, the frequency of pulses used is $\mathrm{f}=54$ $\mathrm{kHz}$; which leads to a wavelength of $\lambda=5.5$. The transducers used have a diameter of $4.95 \mathrm{~cm}$. The results are collated in table 3 .

Table 3. Ultrasonic velocities and pulling forces of mortars on different supports

\begin{tabular}{|c|c|c|c|c|c|c|}
\hline Mortar & Support & $\begin{array}{c}\text { Thickness } \\
\text { (cm) }\end{array}$ & Reference & Position & $\begin{array}{l}\text { speed } \\
(\mathrm{m} / \mathrm{s})\end{array}$ & $\begin{array}{l}\text { Force } \\
(\mathrm{N})\end{array}$ \\
\hline \multirow{8}{*}{$\begin{array}{l}\text { Prepared } \\
\text { mortar }\end{array}$} & \multirow{16}{*}{ concrete } & \multirow[t]{4}{*}{ 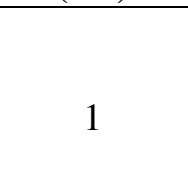 } & \multirow{4}{*}{ MP1_B } & 1 & 3043 & 827 \\
\hline & & & & 2 & 3051 & 813 \\
\hline & & & & 3 & 2583 & 669 \\
\hline & & & & 4 & 2661 & 719 \\
\hline & & \multirow{4}{*}{2} & \multirow{4}{*}{ MP2_B } & 1 & 2880 & 609 \\
\hline & & & & 2 & 2378 & 407 \\
\hline & & & & 3 & 2059 & 315 \\
\hline & & & & 4 & 1931 & 323 \\
\hline \multirow{8}{*}{$\begin{array}{l}\text { Industrial } \\
\text { Mortar }\end{array}$} & & \multirow{4}{*}{1} & \multirow{4}{*}{ MI1_B } & 1 & 2247 & 989 \\
\hline & & & & 2 & 2158 & 956 \\
\hline & & & & 3 & 2537 & 1100 \\
\hline & & & & 4 & 2730 & 1134 \\
\hline & & \multirow{4}{*}{2} & \multirow{4}{*}{ MI2_B } & 1 & 1794 & 569 \\
\hline & & & & 2 & 2323 & 687 \\
\hline & & & & 3 & 2334 & 765 \\
\hline & & & & 4 & 2432 & 812 \\
\hline \multirow{6}{*}{$\begin{array}{l}\text { prepared } \\
\text { Mortar }\end{array}$} & \multirow{12}{*}{ cinderblock } & \multirow{3}{*}{1} & \multirow{3}{*}{ MP1_P } & 1 & 2772 & 1765 \\
\hline & & & & 2 & 2430 & 1757 \\
\hline & & & & 3 & 2100 & 1605 \\
\hline & & \multirow{3}{*}{2} & \multirow{3}{*}{ MP2_P } & 1 & 2312 & 1281 \\
\hline & & & & 2 & 2321 & 1314 \\
\hline & & & & 3 & 1530 & 1070 \\
\hline \multirow{6}{*}{$\begin{array}{l}\text { Industrial } \\
\text { Mortar }\end{array}$} & & \multirow{3}{*}{1} & \multirow{3}{*}{ MI1_P } & 1 & 2833 & 2100 \\
\hline & & & & 2 & 3142 & 2255 \\
\hline & & & & 3 & 2966 & 2187 \\
\hline & & \multirow{3}{*}{2} & \multirow{3}{*}{ MI2_P } & 1 & 1934 & 1564 \\
\hline & & & & 2 & 2385 & 1722 \\
\hline & & & & 3 & 2283 & 1755 \\
\hline
\end{tabular}




\subsection{Effect of mortar thickness}

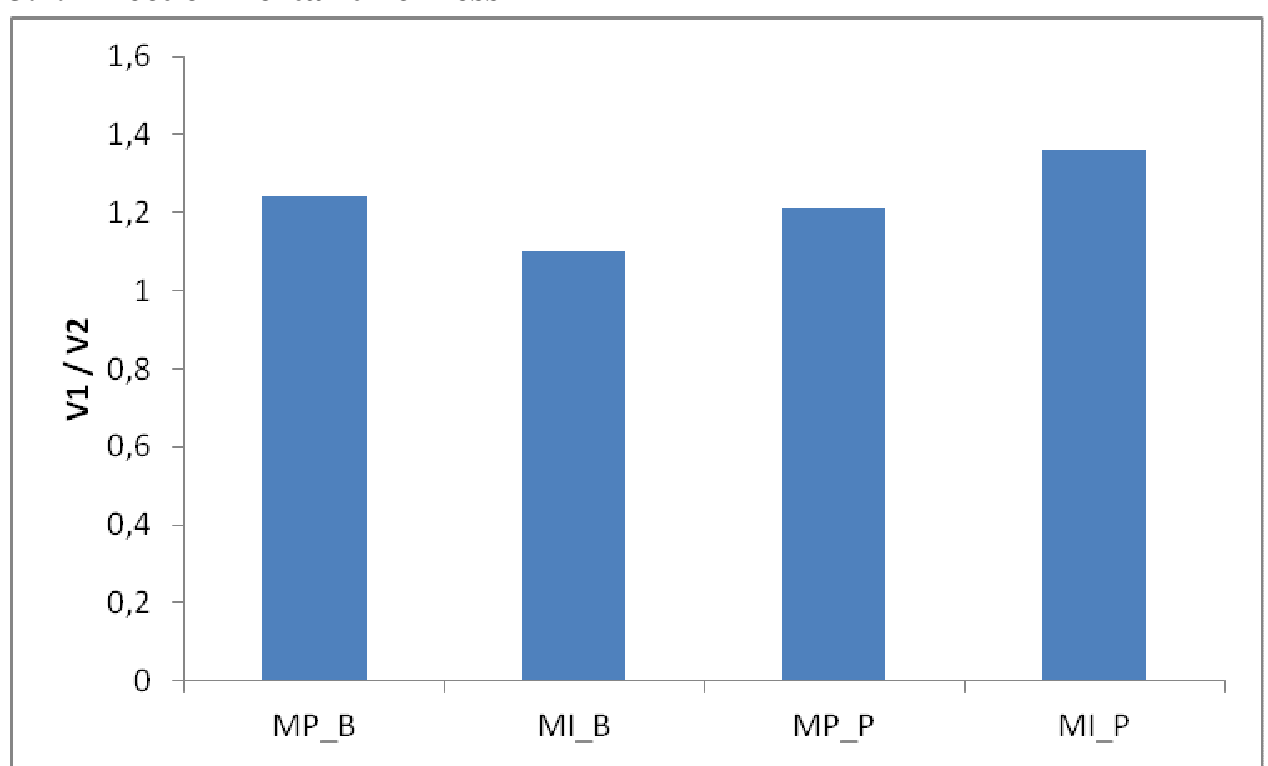

Fig. 3. Effect of thickness on average velocities of different mortars

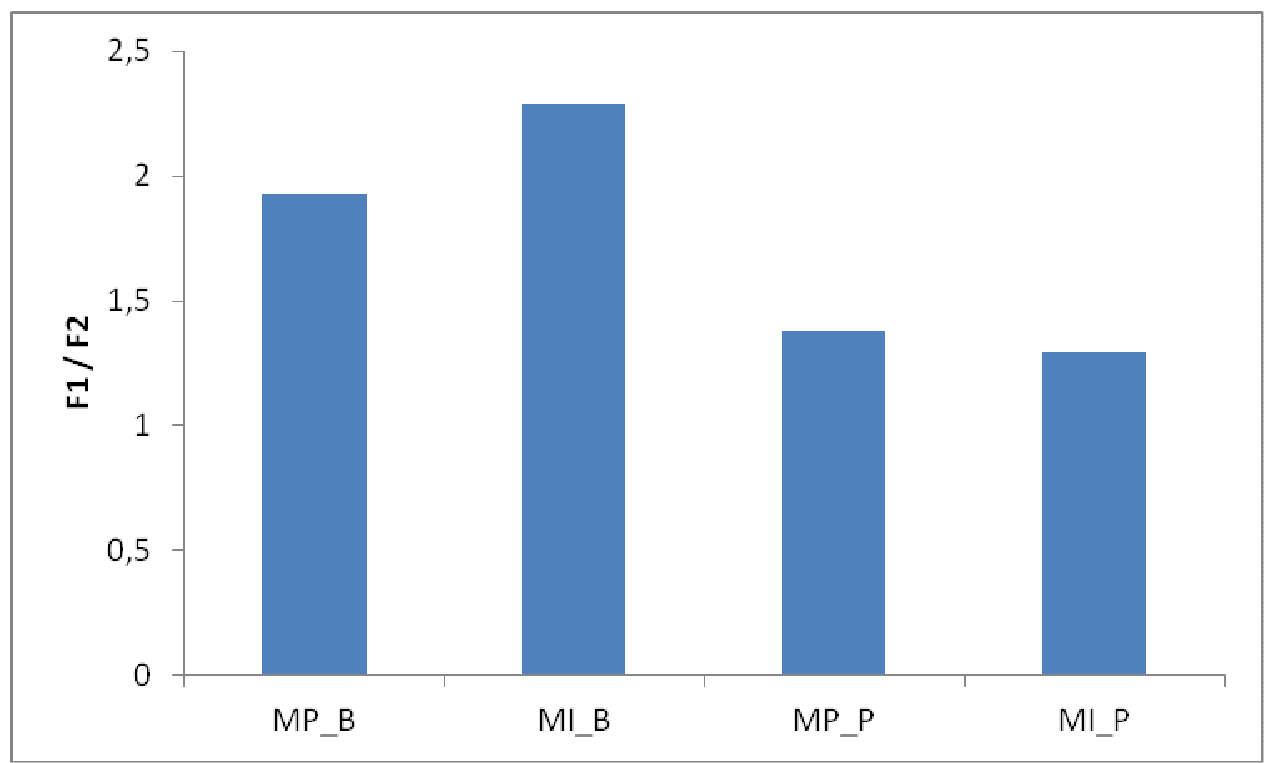

Fig. 4. Effect of thickness on the average breakout forces of different mortars 
Increasing the thickness of the various mortars from $1 \mathrm{~cm}$ to $2 \mathrm{~cm}$ resulted in a decrease in ultrasonic velocities of $10 \%$ to $36 \%$. The effect of the variation of the thickness is accentuated for the pulling force with a maximum decrease which exceeds $200 \%$.

The decrease in velocity, because of the increase in thickness, is less sensitive to the nature of the support, while the pulling force is more affected. The concrete support gives the maximum decrease of adhesion $(200 \%)$ while the cinder block support causes a maximum decrease of less than $40 \%$ (Fig 3-4).

\subsection{Correlations between ultrasonic velocities and pulling forces}

The fact of being interested in the evaluation of the pulling force with all the mortars and their supports, from the surface ultrasonic velocities leads to important uncertainties (Fig 5-8). In addition to the composition of mortars and supports and their surface conditions, carrying out measurements under different experimental conditions can cause variations in velocity [22].

The temperature or poor positioning of the transducers can influence the travel time of the surface ultrasonic wave $[9,25]$.

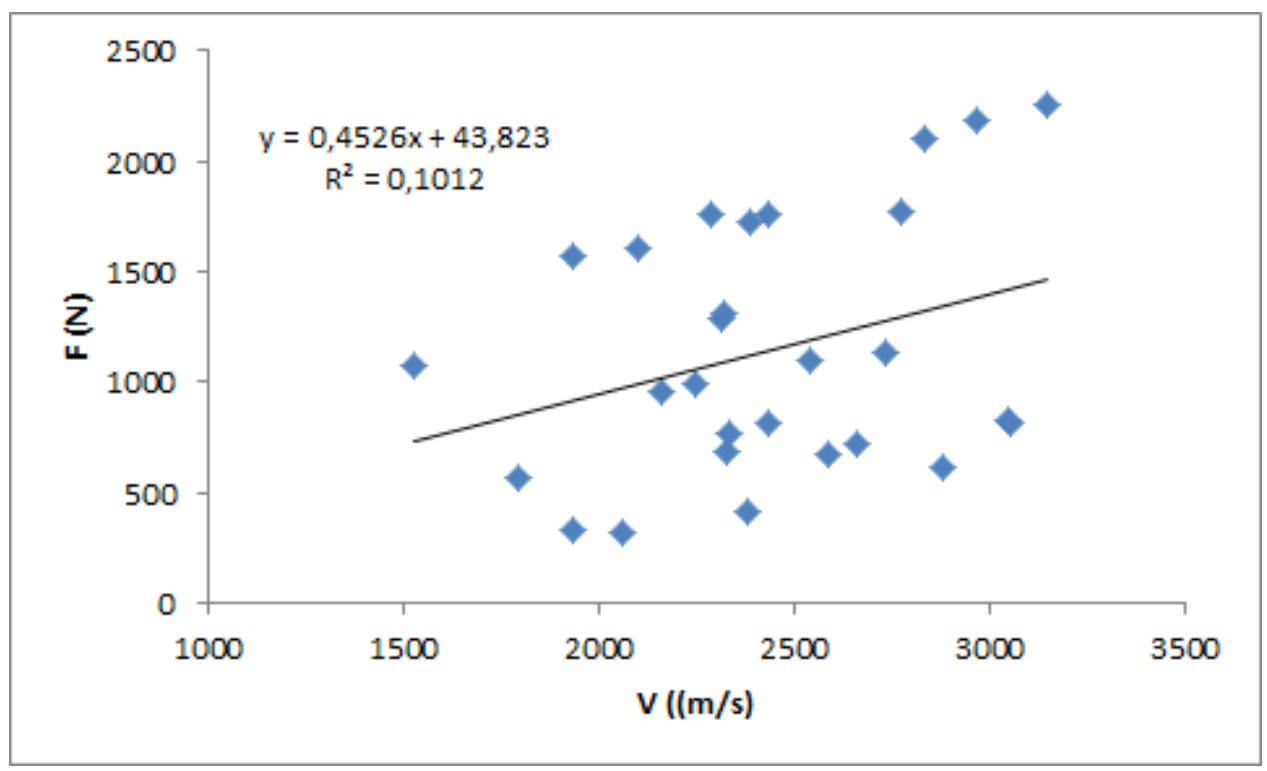

Fig. 5. Relationship between ultrasonic velocities and pulling forces (concrete support) 


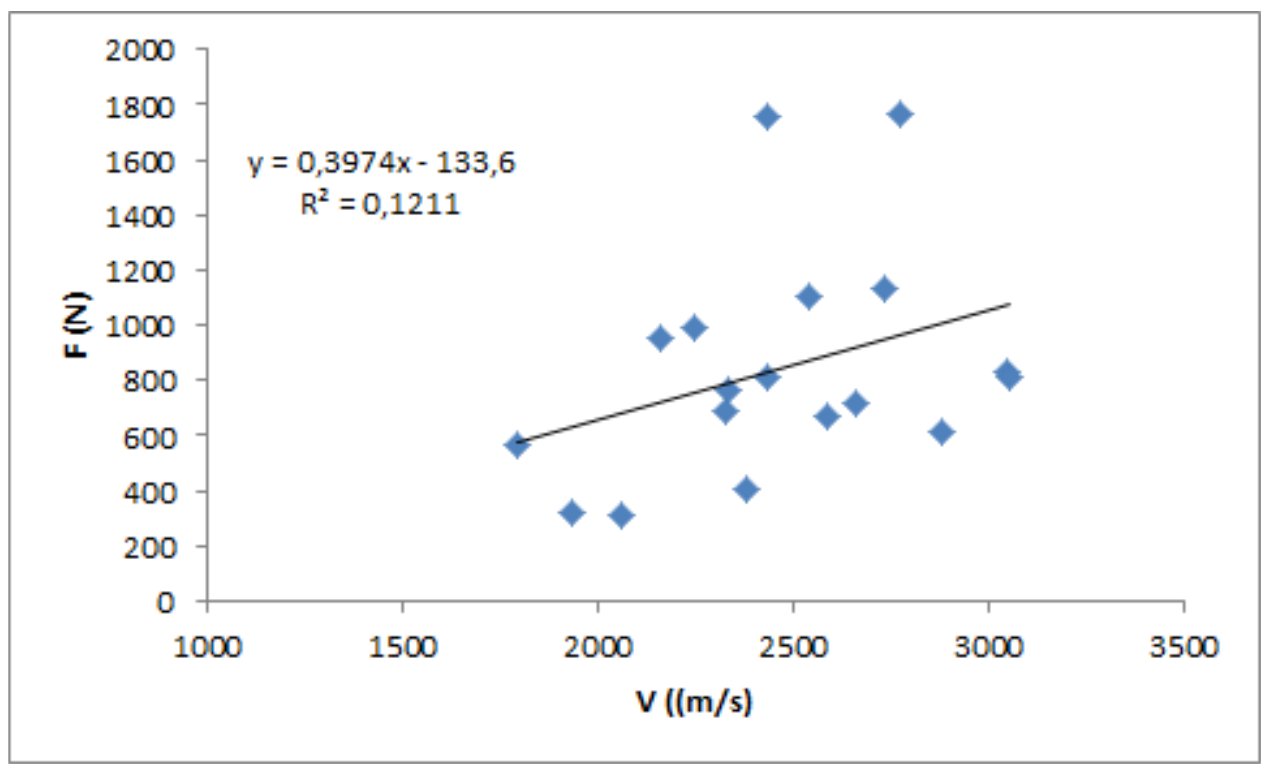

Fig. 6. Relationship between ultrasonic velocities and pulling forces (cinder block support)

The various mortars, as well as their different supports, have different compositions and surface states. It is also noted that the depth of penetration of the Rayleigh wave is directly related to its wavelength. These observations led us to take an interest in each individual case, show the relationship between the ultrasonic velocities and the pulling forces respectively for concrete and cinder block supports.

The estimate of adhesion from surface ultrasonic velocities is satisfactory and has correlation coefficients ranging from 0.79 to 0.98 . 


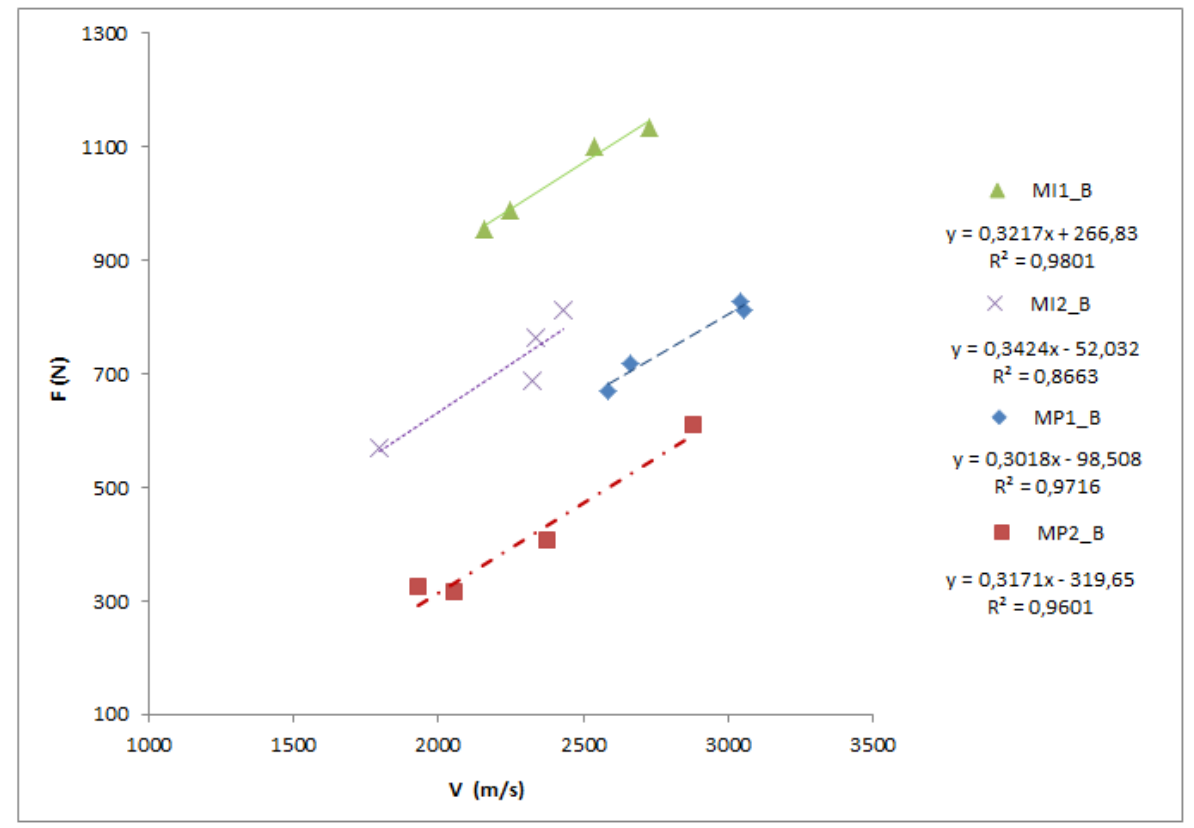

Fig. 7. Correlations between velocities and pulling forces (concrete support)

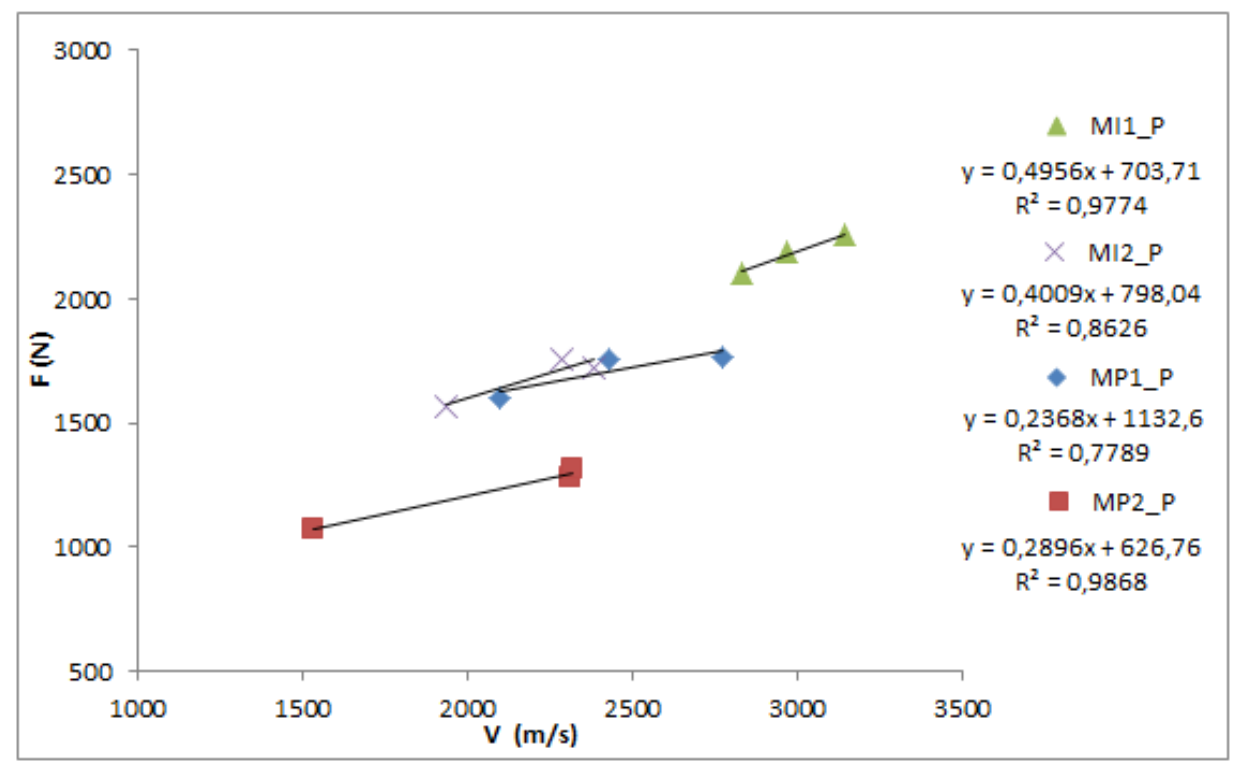

Fig 8. Correlations between velocities and pulling forces (cinder block support) 
Increasing the thickness of the industrial mortar leads to a loss of quality of the relationship between the velocities and the pulling forces of $14 \%$ for both support types (concrete and cinder block).

For the prepared mortar, the increase in thickness did not affect this relationship in the case of the concrete support $\left(\mathrm{R}^{2}=0.97\right.$ for $\mathrm{e}=1 \mathrm{~cm}$ and $\mathrm{R}^{2}=0.96$ for $\mathrm{e}=$ $2 \mathrm{~cm})$. For the cinder block support, an increase in thickness led to a better accuracy of this relationship $\left(\mathrm{R}^{2}=0.79\right.$ for $\mathrm{e}=1 \mathrm{~cm}$ and $\mathrm{R}^{2}=0.98$ for $\left.\mathrm{e}=2 \mathrm{~cm}\right)$. The velocity of the surface wave is influenced by the increase in porosity which decreases the propagation while the water content increases $[6,21]$.

The absorption of water contained in the mortar by the concrete support is lower than the cinder block support. This reflects the sensitivity of the variation of the thickness in the case of the cinder block.

\section{CONCLUSION}

We were interested in estimating the adhesion of mortars using the ultrasonic velocities of surface waves and studying the relationship between the Rayleigh velocity and pulling force for two types of mortars on two different supports, and for two thicknesses of mortar. Access to a single face of the element to be examined makes the surface waves better adapted to the control of the structures. The experimental results show a decrease of ultrasonic velocity with the increase of the thickness of the mortar. This velocity is less sensitive to the nature of the support whereas the pulling force is more affected. The absorption of the water contained in the mortar is lower in the concrete support than in the cinder block support. This reflects the sensitivity of the variation of the effect of the thickness in the case of the cinder block. The effect of the variation of the thickness is accentuated for the pulling force while the concrete support suffers more diminution of adhesion than the cinder block.

The evaluation of the pulling force of all mortars and their supports from the surface ultrasonic velocities has a low linear correlation. This is due to the composition of the mortars as well as the supports, and their surface conditions. Looking at each mortar on each support individually led to an acceptable estimate of mortar adhesion from surface ultrasonic velocities. These linear correlations have correlation coefficients $\left(\mathrm{R}^{2}\right)$ between 0.79 and 0.98. A reference adhesion curve should now be developed for a given type of mortar and support. The obtained results also indicate the need for further investigation to improve the accuracy of the use of ultrasonic pulse velocity to estimate the pulling force adhesion. 


\section{REFERENCES}

1. Azevedo, ARG et al. 2020. Analysis of the compactness and properties of the hardened state of mortars with recycling of construction and demolition waste (CDW), jma t e r r e s t e c h n o 1.202 0; 9(3):5942-5952, https://doi.org/10.1016/j.jmrt.2020.03.122.

2. Azevedo, ARG, França, BR, Alexandre, J, Marvila, MT, Zanelato, EB and Xavier, GC 2018. Influence of sintering temperature of a ceramic substrate in mortar adhesion for civil construction, Journal of Building Engineering, Volume 19, Pages 342-348. https://doi.org/10.1016/j.jobe.2018.05.026.

3. Azevedo, ARG, Marvila, MT, Barroso, LS, Zanelato, EB, Alexandre, J, Xavier, GC and Monteiro, SN 2019. Effect of Granite Residue Incorporation on the Behavior of Mortars. Materials 12, 1449; doi:10.3390/ma12091449.

4. Azevedo, AR, Marvila, MT, Zanelato, EB, Alexandre, J, Xavier, GC and Cecchin, D 2020. Development of mortar for laying and coating with pineapple fibers, Rev. bras. eng. agríc. ambient. vol.24 no.3 Campina Grande . http://dx.doi.org/10.1590/1807-1929.

5. Controls. 2000. Test Equipment and Materials for Buildings and Public Works, 5th Edition 2000.

6. Fnine, A 2006. Auscultation of the skin of concrete by high frequency ultrasonic waves, $\mathrm{PhD}$ thesis of the University of Science and Technology of Lille, France.

7. Goueygou, M, Piwakowski, B, Ould Naffa, S and Buyle-Bodin 2002. Assessment of broadband ultrasonic attenuation measurements in inhomogeneous media. Ultrasonics 40 (1-8), 77-82.

8. Hevin, G, Abraham, OH and Pedersen Campillo, M 1998. Characterization of surface cracks with Rayleigh waves: a numerical model, NDT \& E International. 289-297.

9. Hoblos, J 2004. Evaluation of residual stresses by ultrasonic method taking into account the effects of the microstructure: application to the case of welding. PhD thesis of the University of Lille 1.

10. Hollaway, L and Leeming, M 1999. Strengthening of Reinforced Concrete Structures, Woodhead Publishing Limited, Cambridge, 327 pages.

11. Jin-Yeon, K, Kimberly, E, Kurtis, Laurence, J and Jacobs, AB 2009. Characterization of ultrasonic Rayleigh surface waves in asphaltic concrete. NDT \& E International 42 (7), 610-617.

12. Jones, R 1969. Testing of Concrete by the Ultrasonic Pulse Method. Materials and Structures 2 (10), 253-661.

13. Lamure, A 2007. Adherence and adherence of materials. http: //www.inp toulouse.fr/tice/pdf/01 Extrait_Adhesion_et_Adherence.pdf. 
14. Marvila, MT, Alexandre, J, Azevedo, ARG and Zanelato, EB 2019. Evaluation of the use of marble waste in hydrated lime cement based mortar. Journal of Material Cycles and Waste Management.

15. Marvila, MT, Azevedo, ARG, Alexandre, J, Zanelato, EB, Azeredo, NG, Simonassi, NT and Monteiro, SN 2019. Correlation between the properties of structural clay blocks obtained by destructive tests and Ultrasonic Pulse Tests. Journal of Building Engineering 26. https://doi.org/10.1016/j.jobe.2019.100869

16. Marvila, MT, Alexandre, J, Azevedo, ARG, Zanelato, EB, Xavier, GC and Monteiro, SN 2019. Study on the replacement of hydrated lime by kaolinitic clay in mortars. Advances in Applied Ceramics 118(7), 373-380.

17. Mauroux, $T$ 2011. Impact of drying on the adhesion properties between a mortar and a support - influence of adjuvantation by cellulose ethers. Doctoral Thesis, University of La Rochelle, France.

18. NF DTU 26.1 P1-1, 2008 Building works Mortar plasters work, Part 1-1: Cahier des clauses techniques. P 15-201-1-1.

19. Ould Naffa, S, Goueygou, M, Piwakowski, B and Buyle-Bodin, F 2002. Ultrasonics, 247-251.

20. Seong-Hoon, $\mathrm{K}$ and Boohyun, N, 2019. Automated Surface Wave Measurements for Evaluating the Depth of Surface-Breaking Cracks in Concrete. International Journal of Concrete Structures and Materials, 307321.

21. Tokimatsu, K et al. 1991. Rayleigh wave method. Soils and Foundations 31 (2), 153-163.

22. Toumi, A et al. 2011. Non-destructive evaluation, by ultrasound, of the stress present in prestressing bars in service, 20th French Congress of Mechanics Besançon, August 29 to September 2, 2011.

23. Yu, Z, Yixian, $X$ and Jianghai, $X$ 2011. Analysis of dispersion and attenuation of surface waves in poroelastic media in the exploration-seismic frequency band. Geophysical Journal International 187, 871-888.

24. Zanelato, EB, Alexandre, J, Azevedo, ARG and Marvila, MT 2019. Evaluation of roughcast on the adhesion mechanisms of mortars on ceramic substrates. Mater Struct 52, 53. 2019 https://doi.org/10.1617/s11527-0191353-x.

25. Zhou, X 2006. Parametric study for the determination of residual stresses by the ultrasonic method. PhD thesis of the University of Technology of Troyes.

26. Zoubeir, L, Goueygou, M, Djerbi, A and Kaczmarek, M 2006. Correlation between porosity, permeability, and ultrasonic parameters of mortar with variable water / cement ratio and water content, Cement and Concrete Research, 36 (2006) 625-633. 
Editor received the manuscript: 29.05.2020 